\title{
Chapter 11 \\ Inclusive Education and the UN Convention on the Rights of Persons with Disabilities (UNCRPD)
}

\begin{abstract}
The UNCRPD has already been mentioned in the former chapters. However, there is need of discussing global discourses and questions about the convention and its implementation as it has become a topic of high relevance not only in Ethiopia. Especially article 24 on education of the convention is of major importance for the research at hand. Religion and belief as well as poverty are issues that have already been addressed throughout the study. Hence, it became visible that more factors than disability have to be considered when talking about education and the UNCRPD. Putting these facts in the centre of this chapter allows a critical approach towards questions about the implementation of the UNCRPD.

The main focus is put on questions about how education and inclusion in Ethiopia need to be broadened beyond "disability" and related to other issues of disadvantage. These include aspects of poverty, ethnicity (minorities) and other challenging conditions. Discussing such issues brings forward aspects that are meaningful also on a global level and enriches debates about disability/diversity and culture on the background of the implementation of the UNCRPD.
\end{abstract}

Having brought inclusion and inclusive education into the focus, I want to dedicate the final chapter of this book to one of the most important documents which has guided discussions on disability in the last 10 years: the UN Convention on the Rights of Persons with Disabilities.

It can be argued that the UNCRPD constituted the biggest victory for the disability movement in the three decades of its existence. The Convention has been heralded as a major step forward for disabled people and as representing a paradigm shift on how we think and act about disability. (Meekosha 2011, 1384)

Inequity in education as a global phenomenon is one of the issues which are addressed in the UN Convention on the Rights of Persons with Disabilities (UNCRPD).

The UN (2006) has already been mentioned in previous chapters. There is a need for an in-depth discussion on global discourses and questions about the Convention and its implementation, as it has become a topic of high relevance, not only in 
Ethiopia. Especially Article 24 on education is of major importance for the topic at hand. Point 1 of 5 says:

1. States Parties recognize the right of persons with disabilities to education. With a view to realizing this right without discrimination and on the basis of equal opportunity, States Parties shall ensure an inclusive education system at all levels and lifelong learning directed to:

(a) The full development of human potential and sense of dignity and self-worth, and the strengthening of respect for human rights, fundamental freedoms and human diversity;

(b) The development by persons with disabilities of their personality, talents and creativity, as well as their mental and physical abilities, to their fullest potential;

(c) Enabling persons with disabilities to participate effectively in a free society. (UN 2006, Art. 24, 16)

In short, the Convention aims at a person's “development to the fullest potential to participate effectively" by introducing an inclusive education system. This goal is also based on the human rights discourse and pursues equal opportunities in life. In other words, the ultimate goal is to reach educational equity and equality. This sounds very much like the capability approach, where people's capabilities ("fullest potential") should be converted ("full development") into functionings that are valued by the individual ("participate effectively"). In regard to participating effectively, however, the UNCRPD fails to address the importance for the individual (and the community) to value his/her own achievements and goals. "Participate effectively" sounds like a demand-driven and economically relevant participation in a society rather than reaching a life which the people themselves have reason to value.

In an article comparing Germany, Iceland and Sweden, Biermann and Powell $(2014,680)$ highlight the fact that Article 24 is the one that has been discussed as the most controversial. Referring to Degener (2009), they explicate that the discussions about the choice between inclusive and special schools or an abolishment of special schools resulted in a compromise. Hence, no specific ideas were articulated, but a general human right for inclusive education was declared. The thus created vagueness led to multiple interpretations of inclusive education. Other authors also discuss the problems that persisted after the finalisation of the UNCRPD, in particular regarding inclusive education.

This Convention (UNCRPD) is the outcome of five years of work by a UN Committee on which people with disabilities played a leading role on an equal basis with representatives of national governments. The outcome has been welcomed by the disability movement but many issues proved contentious, not least that of inclusive education. (Mittler 2008, 3)

Regarding the implementation of the UNCRPD, three different dimensions have been identified which challenge traditional perspectives on disability and education in all signing states (Biermann and Powell 2014, 680). Referring to Scott (2008), the authors define them as follows: paradigms of disability and ideals of education as the first dimension (cultural-cognitive), special education as a profession and school as an organisational form as the second dimension (normative), and educational politics and jurisdiction as the third dimension (regulatory) (Biermann 
and Powell 2014, 684). These three dimensions pose major challenges for nation states regarding the implementation of Article 24.

Considering this concept with Ethiopia in mind, it is not easy to fill the three dimensions with content. The knowledge which we have gained from the study, however, provides us with possibilities to think about certain issues regarding cultural-cognitive, normative and regulatory aspects that have to be considered. For instance, we might have gotten an idea of the challenges in the area of education and the history, culture, language and traditions, everyday challenges that form the disability paradigm in this society and are responsible for it; in other words, studies on the situation of children with disabilities like the one at hand are able to provide us with information that helps analyse the challenges and barriers with which a state might be confronted while trying to implement the UNCRPD. But this does not mean that traditional perspectives on disability and education which are challenged by the three dimensions should automatically be changed. In this regard, we also have to be careful about what we define as traditional. When looking at the normative and regulatory dimensions in Ethiopia, we may find that Western standards prevail in the capital. It can therefore sometimes be difficult to identify traditional cultural perspectives. Certain aspects like the influence of religion and belief were easy to identify, whereas more subtle aspects, like the meaning of receiving and providing help, needed a deeper analysis.

This clearly shows that the results of the study provide a basis for identifying important points and elaborating the relevance and extent of the mentioned dimensions - and therefore challenging traditional perspectives - from an Ethiopian point of view. Further studies focusing on complementary aspects would complete the picture of challenges when thinking about the implementation of Article 24 in Ethiopia. Identifying special aspects of a society regarding inclusive education is a relevant tool that must be used if inclusion is to become a reality.

Next to people with disabilities, there are other groups who do not receive education and who are discriminated and left behind. Therefore, we have to broaden our perspective when speaking about inclusion and exclusionary aspects, especially when looking at poverty as an important dimension. We have to address all those people who are disabled, discriminated or/and excluded by society or certain environments or conditions and prevented from active participation if we want to speak about inclusive education and, beyond that, an inclusive society.

Religion and belief as well as poverty were relevant aspects throughout the study, which has shown that these, having a great impact on the life situations of people, are also disabling factors and have to be considered when talking about education and the UNCRPD. Referring to Ingstad (2001), Grech describes:

how the inability to take care of a disabled family member is often bound to the inability to cope with extreme poverty, and not necessarily to negative attitudes and/or lack of concern. At the most basic level, the exclusive focus on negative attitudes and oppression strips disabled people and their households of any form of agency and the ability/possibility to resist and control/change their circumstances, and influence other people's attitudes and behaviours. After all, poor people continue to survive and ensure their own reproduction despite 
the hardships imposed by their physical, social, economic and natural environments, and in the almost regular absence of formal safety nets. $(2011,90)$

This statement demonstrates how important it is to include poverty amongst other risk factors when looking at the situation of people with disabilities. Consequently, difference and diversity are terms that can enrich debates in the context of inclusive education and disability. "An inclusive education system promotes an ethos in which difference is respected and valued, but also actively combats discrimination and prejudice through its policies and actions" (Kaplan et al. 2007, 23). Placing these facts at the centre of this chapter allows a critical approach towards questions about the implementation of the UNCRPD.

\section{Critical Voices Regarding the UNCRPD and Human Rights in General}

One of the most heated human rights debates is indeed whether human rights are a universal or rather a Western concept and, concomitantly, whether they are universally valid or not. (de Sousa Santos 2008, 12)

An evaluation of the UNCRPD must involve the aspect of human rights, since they provide a solid background and information regarding the historical developments. The UNCRPD is based on the original human rights as declared in 1948. Many would agree that human rights should be recognised and implemented on a global level. De Sousa Santos on the other hand argues: "As long as human rights are conceived of as universal, they will operate as a globalized localism, a form of globalization from above" $(2002,44)$. In other words, human rights have been developed by and for mainly Western countries. Looking more closely at the issue especially during the post-war period, it can be found that human rights served the "economic and geopolitical interests of the hegemonic capitalist states" (de Sousa Santos 2002, 45). Consequently, the human rights chapters do not include many aspects from perspectives of majority world countries. Meekosha and Soldatic state that de Sousa Santos positions the human rights discourse in the row of colonial heritage, meaning that the constitution of the human rights is mainly in the hands of a hegemonic North which disregards important "global power imbalances" which play an essential role $(2011,1388)$. In this respect, it is striking that Odysseos and Selmeczi argue that Third World countries (sic) were actually fighting for human rights while trying to be released from the colonial powers. Furthermore, these struggles "were crucial in establishing universal human rights as a paradigm through the emergence of such struggles in the United Nations" (Odysseos and Selmeczi 1034).

It is interesting to observe that these struggles, which also had influences on the development of human rights, did not lead to the Northern countries involving the struggling parties (colonised countries) to a greater extent regarding the concept of human rights. Therefore, human rights cannot be seen as universally applicable 
without considering certain cultural circumstances. One of the main aspects mentioned by de Sousa Santos in this context is human dignity, which may be defined and interpreted differently in different cultures. "As they are now predominantly understood, human rights are a kind of Esperanto which can hardly become the everyday language of human dignity across the globe" (de Sousa Santos 2002, 57). The author sees more incompatible aspects "in the exclusive recognition of individual rights, with the sole exception of the collective right to self-determination $[\ldots]$ in the priority given to civil and political rights over economic, social, and cultural rights; and in the recognition of the right to property as the first and, for many years, the sole economic right" $(2008,14)$.

It is not surprising that here, too - like in the study at hand - the critical point of bringing "Northern" concepts to "Southern" parts of the world receives attention. Turning again to the UNCRPD, Meekosha and Soldatic point their critical voices towards "potential limitations when adopting Northern conceptualisations of disability rights" $(2011,1384)$. In their article, they place the UNCRPD in a cultural, historical and political context in order to be able to approach it in a meaningful way.

Bearing in mind what was discussed earlier about individualist and collectivist cultures, as well as referring to the arguments of de Sousa Santos, the following statement becomes especially interesting:

Individual rights are not a universal concept, but rather reflect the dynamics of an industrialised society. Many countries in the global South are predominantly based on agriculture and subsistence farming, which reflects more traditional community structures. Human rights originated in the Western liberal political tradition, whereas non-metropole cultures have different traditions of emancipatory struggle. (Meekosha and Soldatic 2011, 1388)

In the light of the capability approach, this raises the question to what extent it is related to the individual and how much attention should be paid to groups and communities in this context. There has been some criticism stating that the capability approach is designed only for the individual, although it would also be important to highlight capabilities and functionings, for instance, on the part of communities. From my point of view, this is an essential aspect and cannot be forgotten in the discussion about equal possibilities, living a quality life and reaching functionings that are valued - by the whole community.

Considering rights for people with disabilities on such a background makes it more challenging to think of individual rights in global terms. It is essential to not only point out such differences but also include the meaning of certain power relations between North and South from a Southern perspective (Meekosha and Soldatic 2011, 1389). The striking conclusion that Meekosha and Soldatic draw from that is: "Given the close connection between poverty and disability, it could be argued that a redistribution of power and wealth both between rich and poor countries and within poor countries could have more impact on the lived experience of disabled people in the global South than would human rights legislation" (Meekosha and Soldatic 2011, 1389). 
Reflecting on this argument makes it clear that not only the implementation of rights for people with disabilities is at issue but also a much greater change of relations on a global level.

However, referring to the UNCRPD, again dimensions such as history, tradition, culture, current situation and challenges of a society are essential and have to be regarded in the South when trying to implement a convention that has been mainly developed by countries of the North. Even though there is justifiable criticism of the Northern influence in the context of international conventions and other documents (see, e.g. the chapter on the ICF in this book), the importance of approaching issues like rights for people with disabilities cannot be ignored. However, what has to be highlighted is the significance of the participation and involvement of the majority world in all contexts. In his book "The idea of justice", Amartya Sen argues that human rights are ethical confirmations that the freedoms at which those rights point are of major importance. Therefore, those freedoms should be the starting points for discussing the relevance of human rights.

The importance of freedoms provides a foundational reason not only for affirming our own rights and liberties, but also for taking an interest in the freedoms and rights of others going well beyond the pleasures and desire-fulfilment on which utilitarians concentrate. (Sen 2009, 367)

Consequently, Sen concludes that agreement is needed for the social framework of human rights, meaning the importance which certain freedoms have in a society.

In Ethiopia it seems that certain aspects of the human rights declaration and/or the UNCRPD have gained more or less importance. The Ethiopian government signed the UNCRPD in 2007 and ratified it in 2010. However, it did not sign and ratify the optional protocol (UN Enable, online; FDRE 2012). The optional protocol is important because international complaints are possible only by ratifying this document. This means that people who feel that one of those rights has been violated can report to the international authority in Geneva (Bürli 2015, 63).

In spite of this, the Federal Democratic Republic of Ethiopia stated that, within the implementation process of the UNCRPD, a program of human rights training across the country has taken place. Amongst the people involved were law enforcement officers and other professionals of jurisdiction. These trainings were supported financially by the Norwegian government. Additionally, ethical education - including ideals of human rights - is being taught in primary, secondary and tertiary level schools (FDRE 2012, 32). Having education as a human right, Ethiopia is also trying to reach goals of education for all. "A national Council on inclusive education and training has been set up to promote inclusive policy and the special needs education strategy throughout the country" (FDRE 2012, part 2: 39). What becomes apparent here is that human rights seem to play a major role in the ongoing political discussions about education in Ethiopia. ${ }^{1}$

\footnotetext{
${ }^{1}$ However, there are many critical voices regarding human rights in Ethiopia.
} 
Accentuating the power relations between North and South, it is easy to draw a line to issues of the rights of people with disabilities by looking at the dynamics which they provoke: "It is important to contextualise violations of the rights of disabled people not only in terms of the struggles in the global North, but also in terms of power relations between North and South and within the global South" (Meekosha and Soldatic 2011, 1389). Grech also points at the first part of this statement when saying that "relationships of power" are often left out in discussions about transferring knowledge from West to South. Furthermore, he highlights the problematic aspect of adopting a Western "language of "rights"” (Grech 2011, 88). Another challenging point identified by the author is the fact that disability studies focus on disability in the West. This presents a very Eurocentric or Western view on disability in the academic field. "[...] Western disability studies and its tenets, notably the social model of disability and the language of 'rights', are transferred indiscriminately from North to South and absorbed almost unquestionably by development agencies, southern organisations and other intermediaries" (Grech 2011, 88). He goes on to criticise the process of knowledge from the West being generalised and transferred to the South, "where critical issues related to context, culture, economy, history, community and relationships of power among others are often bypassed or reframed to accommodate a minority world view" $(2009,88)$. Similar arguments can be made when speaking about human rights. This is why de Sousa Santos concludes that human rights are "only universal when they are viewed from a Western standpoint" (2008, 12).

In the context of the capability approach - which according to Nussbaum is one species of a human rights movement - she argues against de Sousa Santos. She states: "It has frequently been said that the human rights movement [...] is Western in origin, and that the endorsement of international human rights norms as major human goals thus reinforces the subordination of non-Western cultures to a Western ideology" $(2011,102)$. Next, she raises the point that lots of the values included in the human rights catalogue had existed long before in Indian and Chinese cultures. She therefore concludes that the argument of another kind of "imperialism" does not have enough substance $(2011,103)$. However, it is not surprising that lots of the values to be found in the human rights can be found in different cultures. It might thus be important to look not only at values but also at the importance and the power of those values and how they are lived and implemented in a society and in different contexts. Religion and/or God, for example, may play a role as a value (system) in lots of different cultures. However, the implications, the meaning, the power and the influence which it may or may not have are completely different (the same is true when looking at disability). I would like to conclude this discussion with Sen's statement:

The possibility of disagreement always exists in pronouncements about human rights, and critical examination is part of what can be called the discipline of human rights. Indeed, even the viability of claims about human rights [...] is closely linked with impartial scrutiny. (Sen 2009, 370) 
Additionally to the challenges that are provoked through power relations between and within states, one question is still open: how a convention that is not mainly based on Southern norms and beliefs can be implemented in countries of the majority world.

\section{The Implementation of the UNCRPD and Its Challenges}

Despite all the critical arguments laid out in the last chapter, it can be said that disability has become a very important human rights issue over the last decades also in countries of the global South. This change of visibility can be seen on a global level, although mainstreaming of disability happens more or less effectively in different parts of the world. McEwan and Butler state that the positive developments that took place, for instance, in Uganda regarding rights and participation of people with disabilities were only possible because the visibility of the topic had increased (2007). However, there are more possibilities to approach the topic which could be successful in improving the situation for people with disabilities. "Yet, while disability has become a quintessential human rights issue, other discourses and solutions, such as collective rather than individual approaches, have tended to become marginalised" (Meekosha and Soldatic, 2011, 1387).

As already stated, giving preference to collective over individual approaches under certain circumstances is especially meaningful when looking at the study at hand. There, I highlighted the meaning of community, family and other collective structures as most meaningful for people involved in the education of children with disabilities in Ethiopia.

Taking these results as a starting point for implementing Article 24 of the Convention, a sustainable basis could be developed for developing specific and effective steps towards an appropriate inclusive education system. By saying "appropriate inclusive", I want to emphasise the fact that inclusion and inclusive education as a concept also have to be defined including the realities of a particular society, culture and a country as such. In other words, a universally applicable concept of inclusion does not exist.

At this point, it is interesting to look at the agenda for the Sustainable Development Goals (SDG) as adopted in September 2015. In the SDGs that will be relevant for all countries until 2030, goal number 4 clearly speaks about inclusive education: "Ensure inclusive and equitable quality education and promote lifelong learning opportunities for all" (UNDP 2015a). The SDGs are innovative in terms of being relevant for all countries, not only countries of the majority world. Additionally, goal number 4 is not only about primary education but about life-long learning. Next to pre-primary and primary education, this includes technical, vocational and tertiary education. Furthermore, skills for decent work, literacy and numeracy are targeted at. Another goal is education for sustainable development and global citizenship. Last but not least, it is aimed to substantially increase the supply of qualified teachers (UNESCO online). To be able to reach such goals, we need to know 
what can and cannot work and what the people involved need. Working towards the implementation of the UNCRPD only makes sense if it happens on a sustainable basis. This means first and foremost that it has to make sense for teachers, children and parents. Starting with these arguments, it clearly makes sense to look at practices that have proven successful for teachers and families who are already sending their children with disabilities to school (whether it be inclusive or special education).

In many countries, the implementation of Article 24 of the Convention signifies a change from a special education system to an inclusive system. Richardson and Powell (2011), for example, compare different systems of special education. At the end of their book, they find that:

[i]n research on special education, macro-level comparisons have been relatively neglected, especially the explicit comparison of the development of education systems over time. As noted at the outset, the considerable variability has, more often than not, been displayed with the chief intention to affirm cultural variation itself. [...] Lacking are systematic analyses of similarities and differences, especially the principles and the relationships to general education and other neighbouring institutions. (Richardson and Powell 2011, 259)

As mentioned before, the abolishment of special schools and special education in general was much discussed during the development of the UNCRPD. In Ethiopia, education appears to be one of the rights that can be achieved in agreement with other goals of the government.

At this point, according to Richardson and Powell, it would be necessary to go deeper into the educational history of Ethiopia, which was already done at the beginning of this book. In a next step, it would be important to obtain answers to the questions: "What is inclusive education?" Or more precisely: "What does inclusive education mean in the Ethiopian context compared to other contexts?" We would have to think about what kind of inclusive education can be successful in a certain environment and why other kinds cannot.

The establishment of special education - as we understand it in Western contexts - has only just begun in Ethiopia. This means that developments that have taken place in Western countries and led to a very strong system of special education (like in Germany) have not taken place to the same extent in Ethiopia. This could be seen as an opportunity and as a head start when it comes to inclusive education. In other words, Ethiopia is not confronted with having to change excluding structures of institutions that have grown for more than 100 years (e.g. special needs trainings for teachers, special schools, etc.). Some experts who were interviewed during my study argued that Ethiopia could use the non-existence of a strongly grown system of separation for the development of an inclusive system. In this context, Zehle (2015) argues that in Ethiopia it is not the idea to change from an existing system of special education to an inclusive system; instead, the idea is to allow children and young people who have been excluded from national education institutions for more than 100 years to access quality education according to their individual skills and needs. The real challenge for the Ethiopian society hence lies more in changing societal attitudes such as "children with disabilities cannot learn" or "cannot contribute to society" towards more inclusive attitudes where children and people with 
disabilities are seen as valued members of society who can improve the community's well-being. Seeing this from the perspective of the capability approach supports the assumption that well-being in this context cannot be understood only in terms of the individual, since we know that family and community play essential roles when it comes to developing equity and equality in education. Furthermore, the capabilities and functionings which are developed in this way continuously contribute to the individual's as well as the community's (and family's) well-being. The implementation of inclusive education in Ethiopia seems therefore to visualise much more clearly the benefits for individuals and for the community as such.

In Ethiopia, the lack of options to send children with disabilities to school has to be seen in the context of the extremely challenging problem of poverty which most families experience. For people with disabilities, this intersectionality between poverty and disability can have devastating consequences. ${ }^{2}$ Hence, the implementation of the UNCRPD could be one way of offering equal possibilities for people with and without disabilities and people living and not living in poverty.

\begin{abstract}
At the international level, the UN Convention on the Rights of Persons with Disabilities provides a clear framework for disabled people to attain the human rights that previously have been denied to them. The overarching goal in both cases is to ensure that disabled people of all ages have access to at least the same opportunities and life chances as are available to their fellow citizens. Whether or not these opportunities are realised depends in large part on the interest and commitment of civil society, particularly national and local voluntary and professional organisations. (Mittler 2008, 8)
\end{abstract}

As a conclusion of the discussion, the key question that must be asked is how education and inclusion in Ethiopia need to be broadened beyond "disability" to consider other kinds of disadvantage as well. These include aspects of poverty, ethnicity (minorities) and other challenging conditions. Discussing such issues reveals aspects that are meaningful also on a global level. For example, poverty cannot be ignored as a factor that influences families in handling their day-to-day problems while also having a family member with a disability, as already stated earlier. Inclusive education hence has to be seen on the background of the realities of the people and societies. Ethnical conflicts cannot be neglected either when talking about making a society more inclusive. These are interdependent factors that play important roles. Such discussions enrich debates about disability/diversity and culture on the background of the implementation of the UNCRPD - especially inclusive education. The aspect of culture receives additional attention as the UNCRPD is approached from a critical perspective on the grounds of cultural diversity. I am now referring to a quotation which I already cited earlier in this book:

\footnotetext{
${ }^{2}$ For more detail on intersectionality in the context of disability, see, for example, Grech, S. and Soldatic, K. (Eds.) (2016). Disability in the global South. The critical handbook (International Publishing Switzerland, Springer).
} 
In many countries, inclusive education is still thought of as an approach to serving children with disabilities within general education settings. However, internationally, it is increasingly seen more broadly as a reform that supports and welcomes diversity amongst all learners (United Nations Educational, Scientific and Cultural Organization (UNESCO 2001). (Ainscow 2007, 3)

And this may be the key issue in realising inclusive education: to recognise the meaning and importance of diversity amongst all learners in educational environments. This leads to placing disability at the same level as other aspects of individual diversity and backgrounds that influence people on their way to reaching functionings which they have reason to value in the society in which they live.

\section{References}

Ainscow, M. (2007). Taking an inclusive turn. Journal of Research in Special Educational Needs, 7(1), 3-7.

Biermann, J., \& Powell, J. J. W. (2014). Institutional dimensions of inclusive schooling: Comparing the challenge of the UN Convention on the Rights of Persons with Disabilities in Germany, Iceland and Sweden. Zeitschrift für Erziehungswissenschaft, 2014, 17(4), 679-700. 679.

Bürli, A. (2015). Zur Umsetzung der UN-Behindertenrechtskonvention. In A. Leonhardt et al. (Eds.), Die UN-Behindertenrechtskonvention und ihre Umsetzung. Beiträge zur Interkulturellen und International vergleichenden Heil- und Sonderpädagogik (pp. 55-66). Bad Heilbrunn: Klinkhardt.

de Sousa Santos, B. (2002). Toward a multi-cultural conception of human rights. In B. HernándezTruyol (Ed.), Moral imperialism. A critical anthology (pp. 39-60). New York: University Press.

de Sousa Santos, B. (2008). Human rights as an emancipatory script? Cultural and political conditions. In B. de Sousa Santos (Ed.), Another knowledge is possible: Beyond northern epistemologies (pp. 3-40). London: Verso.

Degener, T. (2009). Die UN-Behindertenrechtskonvention als Inklusionsmotor. Recht der Jugend und des Bildungswesens, 57, 200-219.

Federal Democratic Republic of Ethiopia (FDRE) (2012). Implementation of the UN convention on the rights of persons with disabilities (CRPD). (Addis Ababa, FDRE) Retrieved November 23, 2016, from http://www.molsa.gov.et/English/SWD/Documents/ETHIOPIA\%20 Implementation \%20of\%20the \%20UN\%20Convention\%20on\%20the \%20Rights\%20of\%20 Persons\%20with\%20Desabilities\%20Initial\%20Report.pdf

Grech, S. (2011). Recolonising debates or perpetuated coloniality? Decentring the spaces of disability, development and community in the global South. International Journal of Inclusive Education, 15(1), 87-100.

Ingstad, B. (2001). Disability in the developing world. In G. L. Albrecht, K. D. Seelman, \& M. Bury (Eds.), Handbook of disability studies (pp. 219-251). Thousand Oaks: Sage.

Kaplan, I., Lewis, I., \& Mumba, P. (2007). Picturing global educational inclusion? Looking and thinking across students' photographs from the UK, Zambia and Indonesia. Journal of Special Education, 7(1), 23-35.

McEwan, C., \& Butler, R. (2007). Disability and development: Different models, different places. Geography Compass, 1(3), 448-466.

Meekosha, H. (2011). Decolonising disability: Thinking and acting globally. Disability \& Society, 26(6), 667-682. 
Mittler, P. (2008). Planning for the 2040s: everybody's business. British Journal of Special Education, 35(1), 4-10.

Nussbaum, M. C. (2011). Creating capabilities. The human development approach. Cambridge, MA/London: Harvard University Press.

Richardson, J. G., \& Powell, J. J. W. (2011). Comparing special education: Origins to contemporary paradoxes. Stanford: Stanford University Press.

Scott, W. R. (2008). Institutions and organizations. Thousand Oaks: Sage.

Sen, A. (2009). The idea of justice. Cambridge: The Belknap Press of Harvard University Press.

UN. (2006). Convention on the rights of persons with disabilities and optional protocol. NewYork: United Nations.

UNDP. (2015a). The millennium development goals report 2015. Retrieved November 23, 2016, from: http://www.undp.org/content/undp/en/home/librarypage/mdg/the-millenniumdevelopment-goals-report-2015.html

UNDP. (2015b). Sustainable development goals. Goal 4: Quality education. Retrieved November 23, 2016, from: http://www.undp.org/content/undp/en/home/sustainable-development-goals/ goal-4-quality-education.html

UNESCO. (2001). International Bureau of Education. The Development of Education. National Report of Ethiopia by Ethiopian National Agency for UNESCO (Final Version) March 2001. Retrieved on June, 2017, from http://www.ibe.unesco.org/International/ICE/natrap/Ethiopia. pdf

Zehle, J. (2015). Inklusion im äthiopischen Schul- und Bildungskontext. In A. Leonhardt et al. (Eds.), Die UN-Behindertenrechtskonvention und ihre Umsetzung. Beiträge zur Interkulturellen und International vergleichenden Heil- und Sonderpädagogik (pp. 206-214). Bad Heilbrunn: Klinkhardt.

Open Access This chapter is licensed under the terms of the Creative Commons Attribution 4.0 International License (http://creativecommons.org/licenses/by/4.0/), which permits use, sharing, adaptation, distribution and reproduction in any medium or format, as long as you give appropriate credit to the original author(s) and the source, provide a link to the Creative Commons license and indicate if changes were made.

The images or other third party material in this chapter are included in the chapter's Creative Commons license, unless indicated otherwise in a credit line to the material. If material is not included in the chapter's Creative Commons license and your intended use is not permitted by statutory regulation or exceeds the permitted use, you will need to obtain permission directly from the copyright holder.

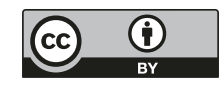

